\title{
Potentiometric Determination of Silver Nanoparticles using Silver Amalgam Electrodes
}

\section{Ladislav Novotný \& Renata Petrankova}

To cite this article: Ladislav Novotný \& Renata Petrankova (2016) Potentiometric Determination of Silver Nanoparticles using Silver Amalgam Electrodes, Analytical Letters, 49:1, 161-168, DOI: 10.1080/00032719.2015.1045584

To link to this article: http://dx.doi.org/10.1080/00032719.2015.1045584

Accepted author version posted online: 11

Sep 2015.

Published online: 11 Sep 2016.

Submit your article to this journal $₫$

Џll Article views: 37

Q View related articles 5

View Crossmark data $[7$ 


\title{
ELECTROCHEMISTRY
}

\section{Potentiometric Determination of Silver Nanoparticles using Silver Amalgam Electrodes}

\author{
Ladislav Novotný and Renata Petrankova \\ Faculty of Chemical Technology, Institute of Environmental and Chemical Engineering, University Pardubice, \\ Pardubice, Czech Republic
}

\begin{abstract}
A new approach to potentiometric measurements using an advanced amalgam electrode is reported. The conditions for the potentiometric determination on silver solid amalgam electrodes to determine total silver as colloidal silver nanoparticles are described. Proper calibration procedure was demonstrated by the potential and logarithmic concentration dependence at the silver amalgam and reference silver disc electrodes for aqueous silver nitrate, as both electrodes conformed to the Nernst equation with the slopes of approximately $+58 \mathrm{mV}$. However, analogous measurements using the silver solid amalgam electrode of silver nanocolloidal solutions provided a slope of $-43 \mathrm{mV}$. Although this value did not match the theoretical result for the Nernst equation, the device allowed the determination of total silver in these solutions. Under the same conditions, no useful calibration dependence was obtained using the silver electrode for the silver colloids.
\end{abstract}

\section{ARTICLE HISTORY}

Received 31 October 2014

Accepted 19 April 2015

\section{KEYWORDS}

Potentiometry; silver amalgam electrodes; silver colloid nanoparticles

\section{Introduction}

In recent years, there is a growing interest in the determination of silver in aqueous solutions because of industrial use, dental and laboratory applications, and special products based on colloidal silver or nanosilver for health purposes (disinfection, etc.) (Dror-Ehre et al. 2009; Lara et al. 2010; Lee, Song, and Lee 2010; Tian et al. 2007; Yoon et al. 2007). There remain several questions related to colloidal silver including (Römer et al. 2011) its toxicity and temperature/photosensitive stability. Different species often affect the concentrations of its free cations. In solutions, used in the medical field or industry, the concentration of silver in colloidal or ionic form is also influenced by stabilizers, such as saccharides (Tolaymat et al. 2010) or biomolecules (Asharani et al. 2008). From an environmental point of view, there is significance in monitoring silver concentrations.

In well-equipped analytical laboratories, atomic absorption spectroscopy (Oprsal et al. 2013), inductive coupled plasma - optical emission spectroscopy or mass spectrometry (ICP-OES or MS), and flow injection analysis have been employed (Kobylinska et al. 2010). However, there is interest in the development of simple and widely accessible methods. Recent reports suggested (Novotny 1998b, 2006, 2007, 2014; Novotny, Petrankova, and

CONTACT Ladislav Novotný nvt.l@seznam.cz E Faculty of Chemical Technology, Institute of Environmental and Chemical Engineering, University Pardubice, Studentska 573, 53210 Pardubice, Czech Republic.

This paper is part of a special issue of papers presented at the Modern Electrochemical Methods XXXIV (in Jetřichovice, Czech Republic)/47th Heyrovský Discussion (in Třešt', Czech Republic) Conferences. 
Kabutey 2014) the new possibilities in this direction, based on potentiometry with amalgam electrodes. For example, silver (solid) amalgam electrodes (often denoted AgSAE and in this paper more generally as AgAE) (e.g., Novotny 1997a, 1997b, 1998b; 2001a, 2007; Novotný and Yosypchuk 2000; Yosypchuk and Novotny 2002) were employed for voltammetry for environmental and health applications (e.g., Novotný and Yosypchuk 2000; Jelen et al. 2002; Yosypchuk and Novotny 2002; Fadrná et al. 2004; Kuchariková et al. 2004; Barek et al. 2007; Yosypchuk and Barek 2009; Šelešovská et al. 2012; Bandžuchová et al. 2013; Brycht et al. 2013; Vajdle et al. 2014) like renewed stationary mercury electrodes (Novotny 2001b). However, no direct potentiometric measurements using these silver amalgam electrodes have been published to date.

The objective of this communication was to investigate the conditions for the application of potentiometry on silver amalgam electrodes AgAE for the determination of silver in solutions containing silver colloidal nanoparticles and silver ions. The results obtained on the AgAE were compared with those obtained using a silver disc electrode, AgE.

\section{Experimental}

For measurements, the instrumentation employed a potentiometric block BM 551 (Laboratory Instruments, Tesla, Prague) with an impedance of $10^{9} \Omega$. The AgAE, AgE, reference electrodes, a magnetic stir bar, and a gas-inlet were inserted into the solution in the closed glass cell. A modified electrode $\mathrm{Ag} / \mathrm{AgCl}(3 \mathrm{M} \mathrm{KCl})$ (Electrochemicke Detektory, spol. s r. o., Turnov), with a salt bridge containing $0.1 \mathrm{M} \mathrm{KNO}_{3}$ served as the reference. The solutions were prepared from demineralized water $(<0.1 \mu \mathrm{S} / \mathrm{cm}$, from the Milli-Q Plus water-purification system Millipore, Bedford, USA) and reagent-grade chemicals $\left(\mathrm{AgNO}_{3}, \mathrm{KNO}_{3}\right.$, and $\left.\mathrm{KCl}\right)$. The experimental arrangement included a cell and a stand of the Eco-Tribo Polarograph (Novotny 1998a, 2001a) (Eco-Trend Plus, Prague) and accessories. For measurements in the absence of atmospheric oxygen, 99.99\% nitrogen was bubbled through the solution for approximately 5 minutes. Experiments were performed at laboratory temperature, $293 \mathrm{~K}$. The temperature coefficient of potential $E$ measurements was lower than $\pm 0.4 \mathrm{mV} / \mathrm{K}$.

The AgE was prepared from a silver wire of $0.5 \mathrm{~mm}$ diameter either by sealing into a conical tapered glass capillary or by its tight fit in an inert plastic tip of a micropipette. Cutting and polishing of the orifice of this electrode resulted in a smooth silver disk electrode. The silver amalgam electrode, AgAE of diameter $0.5 \mathrm{~mm}$, was prepared by applying freshly prepared amalgam in the aforementioned inert plastic tip resulting in the potentiometric plastictip silver amalgam (solid) electrode AgAE or AgSAE. The plastic-tip electrode was first reported by Novotný, Kůta, and Smoler (1978) andNovotny (1981) and followed by other applications (e.g., Novotny 1998b; Novotný 2000, 2007). The active surface in the form of a disk was renewed by cutting the plastic tip with a razor blade resulting in a length of approximately $0.5 \mathrm{~mm}$. Of course, AgAE-electrodes may also be renewed by polishing their orifice using, e.g., a glass or polyethylene plate or a $0.3-\mathrm{mm}$ suspension of alumina.

Analogously to the previous work (Oprsal et al. 2013), a $1 \mathrm{mmol} / \mathrm{L}$ stock solution of colloidal silver nanoparticles was prepared by the chemical reduction of silver nitrate by glucose. Amounts of $10 \mathrm{~mL}$ of distilled water, $10 \mathrm{~mL}$ of $5-\mathrm{mM}$ silver nitrate, $10 \mathrm{~mL}$ of 25-mM ammonia, $10 \mathrm{~mL}$ of $50-\mathrm{mM}$ sodium hydroxide solution, and $10 \mathrm{~mL} 50-\mathrm{mM}$ glucose were mixed. The resulting solution was stirred at room temperature for fifteen minutes and 
stored in a dark bottle. Solutions with lower concentrations were prepared through dilution of the stock.

Concentrations of silver in samples were determined using inductively coupled plasma optical emission spectrometry (Integra XL2, GBC, Dandenong, Australia) (Oprsal et al. 2013). The limits of detection and quantification for silver were $0.06 \mu \mathrm{M}$ and $0.20 \mu \mathrm{M}$, respectively.

Linear least-square regression in OriginPro 7.5 (OriginLabCorporation, USA) was used for the evaluation of the linearity of potential and logarithm of concentration relationships. The slope and intercept were reported with $95 \%$ confidence intervals.

\section{Results and discussion}

The measurements and the arrangement used were based on preliminary findings (Novotny 1998b, 2006, 2007; 2009, 2014; Novotny, Petrankova, and Kabutey 2014). Both served as working detection potentiometric electrodes, one of which was a silver disk electrode AgE and the other a silver solid amalgam electrode AgAE with a silver concentration of $35 \%(w / w)$. Measurements were carried out under the same conditions using the AgAE and $\mathrm{AgE}$ and the results were compared.

Proper functioning of the mentioned technique and procedure were verified by the potential $E$ versus logarithm concentration (c) dependences in $\mathrm{AgNO}_{3}$ solutions on the $\mathrm{AgAE}$ and on the reference silver disc electrode, AgE. As expected, the presence of dissolved oxygen significantly influenced the measurements. The interference is documented in Figure 1 where the dependences of potential $E$ on the logarithm of concentrations $c$ of the solution $\mathrm{AgNO}_{3}$ are presented both in the presence and absence of oxygen. Following the introduction of nitrogen, the AgAE and AgE provided approximately the same profiles Eversuslogc with the theoretically expected (Scholz 2002) slope $\delta E / \delta \log c=58 \mathrm{mV}$. When dissolved oxygen was present, the $E-\log c$ graphs for $\operatorname{AgAE}$ and $\mathrm{AgE}$ provided low sensitivity (i.e., $\delta E / \delta \log c$ ).

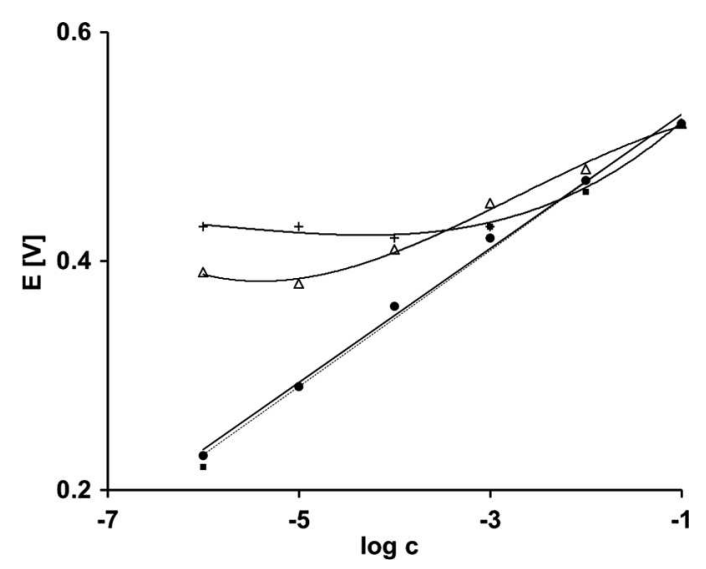

Figure 1. Dependence of potential $E$ on the concentration (c) of $\mathrm{AgNO}_{3}$ on the $(\cdot)$ solid silver amalgam electrode after removal of dissolved oxygen, ( $\mathbf{(})$ the silver electrode after removal of dissolved oxygen, $(+)$ solid silver amalgam electrode in the presence of dissolved oxygen, and $(\Delta)$ the silver electrode in the presence of dissolved oxygen. 
The repeated introduction of nitrogen (see Table 1) of the same solution obtained $E$ vs. $\log c$ linear dependences with a slope approaching the theoretical value $2.303 R T / F$ (Scholz 2002), and again the higher slope was observed on AgAE. Nevertheless, in comparison with the previous case (Figure 1 and Table 1), the $E-\log c$ dependences were shifted by more than $100 \mathrm{mV}$ to lower values of $E$. Namely, when the electrodes were maintained between experiments with dissolved oxygen, consecutively obtained dependences of $E-\log c$ measured under nitrogen were shifted in potential while maintaining the linear relationship between potential and the logarithm of concentration. The cause was apparently due to the formation of insoluble oxides, hydroxides, or other products on the electrodes.

Table 1 shows that additional consecutive measurements of $E-\log c$ (by the addition of nitrogen prior to potentiometry measurement) for one month provided for the AgE and AgAE (without renewal their surface) values of slope $k_{i}$ close to the theoretical value, although small shifts of the $E-\log c$ curves occurred. The most significant changes in potential $E$ occurred in the concentration range from $3 \times 10^{-5}$ to $3 \times 10^{-2} \mathrm{M} \mathrm{Ag}^{+}$. The character of the plot remained approximately constant without renewal of the electrode surface, although the curves were shifted along the potential axis. Variations of the potential following deaeration occurred with both electrodes at $\pm 1 \mathrm{mV}$. These experiments therefore confirmed significant interferences of atmospheric oxygen and the necessity of its removal.

Therefore, further experiments on AgAE with solutions containing various concentrations $(c)$ of colloidal silver (nanosilver) were performed in deaerated solutions. In this case, however, the potential $E$ with increasing concentration of colloidal silver $c$ (Figure 2) did not increase, but rather decreased according to EQ1, not conforming to the Nernst equation. A linear relationship between potential and the logarithm of concentration had an analytically utilizable slope $\delta E / \log c=-43 \mathrm{mV}$. The behavior of colloidal silver may contribute to its speciation in the presence of silver ions.

$$
\mathrm{E}[\mathrm{V}]=(-0.0428 \pm 0.0023) \log c+(0.3175 \pm 0.0042) ; R=-0.9887)
$$

One of the reasons for this decrease may be connected with the observation that after complete separation of colloidal silver particles with a centrifuge, inductive coupled plasma-optical emission spectroscopy measurements showed that there was no silver present in the form of $\mathrm{Ag}^{+}$ions. More precisely, the residual concentration of $\mathrm{Ag}^{+}$was below the limit of

Table 1. Parameters of the dependence $E=k_{i} \log c+q_{i}$ involving the concentration of AgNO3 on the solid silver amalgam electrode or silver electrode, where $i=1,2,3$ : (1) renewal of electrode surfaces and deaeration with nitrogen; (2) saturation by atmospheric oxygen and deaeration with nitrogen; (3) measurements following month including procedure (2).

\begin{tabular}{lcc}
\hline Parameters & Solid silver amalgam electrode & Silver electrode \\
\hline$k_{1}[\mathrm{~V}]$ & $0.0585 \pm 0.0018$ & $0.0594 \pm 0.0033$ \\
$q_{1}[\mathrm{~V}]$ & $0.5866 \pm 0.0073$ & $0.5880 \pm 0.0131$ \\
$R(1)$ & 0.9974 & 0.9920 \\
$k_{2}[\mathrm{~V}]$ & $0.0548 \pm 0.0019$ & $0.0457 \pm 0.0015$ \\
$q_{2}[\mathrm{~V}]$ & $0.4553 \pm 0.0076$ & $0.4266 \pm 0.0059$ \\
$R(2)$ & 0.9968 & 0.9972 \\
$k_{3}[\mathrm{~V}]$ & $0.0585 \pm 0.0035$ & $0.0532 \pm 0.0026$ \\
$q_{3}[\mathrm{~V}]$ & $0.4587 \pm 0.0138$ & $0.4317 \pm 0.0104$ \\
$R(3)$ & 0.9908 & 0.9937 \\
\hline
\end{tabular}




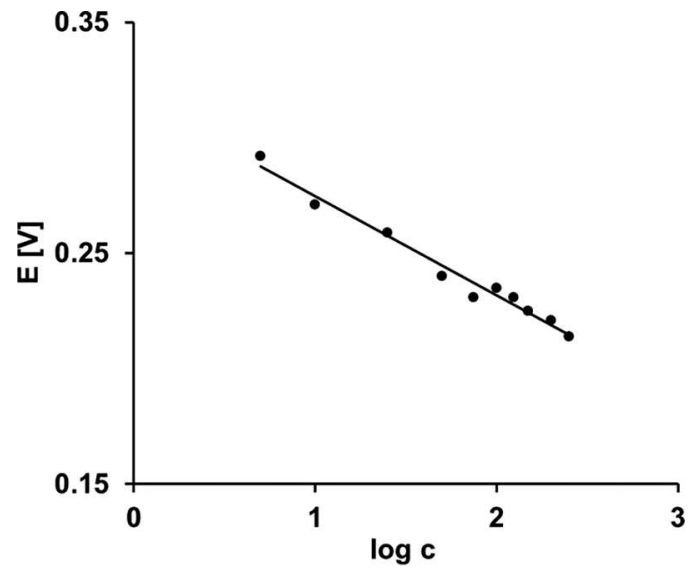

Figure 2. Potential (E) and concentration (c) dependence of colloidal nanosilver after removal of dissolving oxygen using the silver electrode without renewal of the surface.

quantification of this method, which was $0.2 \mu \mathrm{M}$ Ag. Hence, the solutions of colloidal silver contained few free $\mathrm{Ag}^{+}$ions. Nanocolloids (probably covered by $\mathrm{Ag}^{+}$) may contact the electrodes, thereby by increasing the concentration and consequently increasing the size of colloidal particles; hence, their effective contact with the electrode surfaces decreased.

When AgAE was utilized for these applications, changes in potential with the logarithm of the concentration remained linear even after repeated use of AgAE without mechanical renewal over approximately 2 months. Nevertheless, a current renewal by slight polishing of its orifice using a plastic or glass plate was applied.

The influence of the presence of $\mathrm{Ag}^{+}$on the $E-\log c$ dependence of colloidal silver is illustrated in Table 2. The absolute value of the slope $(\delta E / \delta \log c)_{c_{A g}+}$ decreased with increasing concentration $c_{\mathrm{Ag}^{+}}$. Within the reproducibility of the measurements, no interferences of $\mathrm{Ag}^{+}$below concentrations of approximately $2 \mu M$ were observed. However, on the $\mathrm{AgE}$, sensitive and reproducible changes of $E$ were not obtained under these conditions. The addition of $5-50 \mu \mathrm{M}$ colloidal silver caused a decrease of the slope (sensitivity) $\delta E / \delta \log c_{\mathrm{Ag}^{+}}$by approximately $20 \%$. With respect to the $E-\log c$ dependences, intraday and day-to-day reproducibility of the slopes was $5-6 \%$, whereas the reproducibility of the intercepts were between 1 and $3 \%$. The precision of the potentiometric measurements was $\pm 0.1 \mathrm{mV}$ and their repeatability was $\pm 1-2 \mathrm{mV}$, better values at lower concentrations of silver colloids. The reproducibility of the sensor preparation, from unit to unit, with respect to the potential values was approximately $5 \%$.

Table 2. Parameters of the dependence $E=k_{i} \log c+q_{i}$ involving the concentration $c$ of colloidal nanosilver obtained on the solid silver amalgam electrode at various concentrations $c_{\mathrm{Ag}^{+}}$of $\mathrm{Ag}^{+}$.

\begin{tabular}{lccc}
\hline$c_{A g^{+}}[\mathrm{mol} / \mathrm{L}]$ & $k_{i}[\mathrm{~V}]$ & $q_{i}[\mathrm{~V}]$ & $R$ \\
\hline 0 & $-0.0428 \pm 0.0023$ & $0.3175 \pm 0.0042$ & -0.9887 \\
$1 \times 10^{-5}$ & $-0.0372 \pm 0.0021$ & $0.3190 \pm 0.0048$ & -0.9888 \\
$1 \times 10^{-4}$ & $-0.0301 \pm 0.0019$ & $0.3253 \pm 0.0050$ & -0.9889 \\
$1 \times 10^{-3}$ & $-0.0190 \pm 0.0024$ & $0.3415 \pm 0.0060$ & -0.9705 \\
$1 \times 10^{-2}$ & $-0.0073 \pm 0.0004$ & $0.3997 \pm 0.0011$ & -0.9934 \\
$1 \times 10^{-1}$ & $-0.0066 \pm 0.0005$ & $0.4854 \pm 0.0014$ & -0.9874 \\
\hline
\end{tabular}


After removal of dissolved oxygen, the concentration $c$ of colloidal silver in an unknown sample was performed by measuring $E_{1}$ for a reference solution of analogous composition as the sample at a known concentration $c_{1}$ of silver nanoparticles, $E_{2}$ after addition of a known amount of silver nanoparticles resulting in final $c_{2}$ and $E_{x}$ after addition of the sample allowing determination of the unknown concentration $c_{x}$. Considering the dilution of the sample, the unknown concentration can be calculated from $c_{x}$ using the following equation:

$$
\log c_{x}=\frac{E_{x}-E_{1}}{E_{x}-E_{1}} \log \frac{C_{2}}{C_{1}}+\log c_{1}
$$

Similarly, determining the concentration of $\mathrm{Ag}^{+}$ions in the samples using the linear dependences $E-\log c$ may also be applied.

The standard addition method was employed for the analysis of a model sample containing colloidal silver. The determined value of 8.2 plusmn; $0.6 \mu \mathrm{M} \mathrm{Ag}$ was in good agreement with the value of $8.58 \pm 0.07 \mu \mathrm{M}$ Ag obtained by inductively coupled plasma optical emission spectrometry. In solutions of colloidal silver nanoparticles, the sensitivity of AgAE with respect to concentration was approximately ten-fold-times higher compared with the AgE. Further optimization of the electrode preparation and the analytical parameters will continue.

\section{Conclusions}

The measurements showed the possibility of using potentiometry with silver solid amalgam electrodes AgAE for the determination of total silver concentration in solutions of silver nanoparticles. The potential of the AgAE exhibited a linear dependence on the logarithm of concentration of colloidal silver nanoparticles with a slope of $-43 \mathrm{mV}$. It was necessary to remove oxygen by deaeration with nitrogen for 5 minutes. Under the optimized conditions, a linear relationship between potential and concentration was obtained with a slope close to its theoretical value $R T / F$ (approximately $58 \mathrm{mV}$ ). Even without the renewal of the electrode, the linear profile of the course of curves $E-\log c$ remained equal, but the relationship was shifted on the potential axis with time.

An analytical application using a reference (standard) solution of colloidal silver nanoparticles for the determination of total silver concentration in the analyzed sample was reported. The results obtained on a silver amalgam electrode with measurements made on a silver electrode AgE measured under the same conditions showed that the relationships between potential and concentration were similar on both electrodes. In solutions of colloidal silver nanoparticles, however, the sensitivity at the AgE was lower by a factor ten than at AgAE. Hence, analytical utilization appeared to be unsatisfactory. Measurements on both electrodes in the presence of dissolved oxygen were much less sensitive and reproducible. In summary, this paper described a simple and inexpensive method to determine colloidal silver in aqueous solution.

\section{Funding}

This work was financially supported by the Ministry of Education, Youth, and Sports of the Czech Republic (Development of the Research Organization Project No. 0021627502 and Project No. SGSFChT_2015006). 


\section{References}

Asharani, P. V., Y. L. Wu, Z. Gong, and S. Valiyaveettil. 2008. Toxicity of silver nanoparticles in zebrafish models. Nanotechnology 19: 255102. doi:10.1088/0957-4484/19/25/255102

Bandžuchová, L., R. Šelešovská, T. Navrátil, and J. Chýlková. 2013. Silver solid amalgam electrode as a tool for monitoring the electrochemical reduction of hydroxocobalamin. Electroanalysis 25: 213-22. doi:10.1002/elan.201200365

Barek, J., J. Fischer, T. Navrátil, K. Pecková, B. Yosypchuk, and J. Zima. 2007. Nontraditional electrode materials in environmental analysis of biologically active organic compounds. Electroanalysis 19(19-20): 2003-14. doi:10.1002/elan.200703918

Brycht, M., S. Skrzypek, V. Guzsvány, and J. Berenji. 2013. Conditioning of renewable silver amalgam film electrode for the characterization of clothianidin and its determination in selected samples by adsorptive square-wave voltammetry. Talanta 117: 242-49. doi:10.1016/ j.talanta.2013.08.048

Dror-Ehre, A., H. Mamane, T. Belenkova, G. Markovich, and A. Adin. 2009. Silver nanoparticle-E. coli colloidal interaction in water and effect on E. coli survival. Journal of Colloid and Interface Science 339: 521-26. doi:10.1016/j.jcis.2009.07.052

Fadrná, R., B. Yosypchuk, M. Fojta, T. Navrátil, and L. Novotný. 2004. Voltammetric determination of adenine, guanine, and DNA using liquid mercury free polished silver solid amalgam electrode. Analytical Letters 37: 399-413. doi:10.1081/al-120028615

Jelen, F., B. Yosypchuk, A. Kourilová, L. Novotný, and E. Paleček. 2002. Label-free determination of picogram quantities of DNA by stripping voltammetry with solid copper amalgam or mercury electrodes in the presence of copper. Analytical Chemistry 74: 4788-793. doi:10.1021/ ac0200771

Kobylinska, A., M. C. Bruzzoniti, C. Sarzanini, and M. Franko. 2010. Determination of colloid silver in drinking water by flow injection analysis with TLS spectrometric UV detection. Journal of Physics: Conference Series 214: 012119. doi:10.1088/1742-6596/214/1/012119

Kuchariková, K., L. Novotny, B. Yosypchuk, and M. Fojta. 2004. Detecting DNA damage with a silver solid amalgam electrode. Electroanalysis 16: 410-14. doi:10.1002/elan.200302874

Lara, H. H., N. V. Ayala-Núñez, L. C. I. Turrent, and C. R. Padilla. 2010. Bactericidal effect of silver nanoparticles against multidrug-resistant bacteria. World Journal of Microbiology and Biotechnology 26: 615-21. doi:10.1007/s11274-009-0211-3

Lee, S. M., K. C. Song, and B. S. Lee. 2010. Antibacterial activity of silver nanoparticles prepared by a chemical reduction method. Korean Journal of Chemical Engineering 27: 688-92. doi:10.1007/ s11814-010-0067-0

Novotny, L. 1981. Development of new types of the mercury electrodes, theoretical consequences and practical application. CSc. thesis, Academy of Sciences of the Czech Republic, Prague.

Novotny, L. 1997a. Design of renewable Hg/Ag meniscus electrodes. In Book of Abstracts of the International Conference Inorganic Environmental Analysis and Quality Assurance: P10, ed. J. M. Marci. Pardubice, Czech Republic: University Pardubice, September 2-5, Spectroscopic Soc.

Novotny, L. 1997b. Design of the renewable Hg/Ag (amalgam) electrode. Czech. Pat. PUV 1997-7103, 6815.

Novotny, L. 1998a. Development of renewed mercury multi-purpose (multi-mode, versatile) microelectrodes, a part of PC-controlled measuring systems (including the PC-ETP). Fresenius' Journal of Analytical Chemistry 362: 184-88. doi:10.1007/s002160051056

Novotny, L. 1998b. New possibilities of electrochemical analysis in biophysics. DSc. thesis, Academy of Sciences of the Czech Republic, Prague.

Novotný, L. 2000. Use of plastic-tip capillaries for polarography/voltammetry and related techniques in HF solutions and glass corroding media. Electroanalysis 12: 1240-42. doi:10.1002/1521-4109 (200010) 12:15<1240::aid-elan1240>3.0.co;2-z

Novotny, L. 2001a. A renewable composite amalgam electrode. Czech. Pat. PV 2001-1, 298623.

Novotny, L. 2001b. Universal mercury electrode system with a miniaturized pen-type sensor. Chemicke Listy 95: 147-49. 
Novotny, L. 2006. The described way and arrangement of electrochemical and related measurements for ready application under common conditions. Czech. Pat. PV/PUV 2006-600, 30527.

Novotny, L. 2007. A measuring system including miniaturized (amalgam) electrodes and plastic-tip arrangements. Czech. Pat. PUV, 2007-19501, 19062.

Novotny, L. 2009. Recent promising miniaturized renewed mercury or related electrodes and plastic sensors. Chemicke Listy 103: 269-69.

Novotny, L. 2014. Potentiometry using new types of special modules and electrodes. Chemicke Listy 108: 777.

Novotný, L., J. Kůta, and I. Smoler. 1978. Electrocapillary studies of fluoride solutions on mercury using polyethylene capillary. Journal of Electroanalytical Chemistry and Interfacial Electrochemistry 88: 161-68. doi:10.1016/s0022-0728(78)80263-0

Novotny, L., R. Petrankova, and A. Kabutey. 2014. The influence of dissolved air on potentiometry using silver/silver ions or colloids interfaces. Book of abstract of the XXXIV. Modern electrochemical method, ed. T. Navratil, M. Fojta, and K. Peckova 118-20. Jetrichovice, Czech Republic: BEST servis Ústí nad Labem, May 19-23, 2014.

Novotný, L., and B. Yosypchuk. 2000. Solid silver amalgam electrodes. Chemicke Listy 94: 1118-20.

Oprsal, J., P. Knotek, M. Pouzar, J. Palarcik, and L. Novotny. 2013. Impact of the silver nanoparticles agglomeration on the results of ecotoxicity tests on aquatic organisms. Chemicke Listy 107: 386-92.

Römer, I., T. A. White, M. Baalousha, J. K. Chipman, M. R. Viant, and J. R. Lead. 2011. Aggregation and dispersion of silver nanoparticles in exposure media for aquatic toxicity tests. Journal of Chromatography A 1218: 4226-33. doi:10.1016/j.chroma.2011.03.034

Scholz, F. 2002. Electroanalytical methods. Berlin, Germany: Springer-Verlag.

Šelešovská, R., L. Bandžuchová, T. Navrátil, and J. Chýlková. 2012. Voltammetric determination of leucovorin using silver solid amalgam electrode. Electrochimica Acta 60: 375-83. doi:10.1016/j. electacta.2011.11.071

Tian, J., K. K. Y. Wong, C.-M. Ho, C.-N. Lok, W.-Y. Yu, C.-M. Che, J.-F. Chiu, and P. K. H. Tam. 2007. Topical delivery of silver nanoparticles promotes wound healing. Chem Med Chem 2: 12936. doi:10.1002/cmdc.200600171

Tolaymat, T. M., A. M. El Badawy, A. Genaidy, K. G. Scheckel, T. P. Luxton, and M. Suidan. 2010. An evidence-based environmental perspective of manufactured silver nanoparticle in syntheses and applications: A systematic review and critical appraisal of peer-reviewed scientific papers. Science of the Total Environment 408: 999-1006. doi:10.1016/j.scitotenv.2009.11.003

Vajdle, O., J. Zbiljić, B. Tasić, D. Jović, V. Guzsvány, and A. Djordjevic. 2014. Voltammetric behavior of doxorubicin at a renewable silver-amalgam film electrode and its determination in human urine. Electrochimica Acta 132: 49-57. doi:10.1016/j.electacta.2014.03.124

Yoon, K.-Y., J. H. Byeon, J.-H. Park, and J. Hwang. 2007. Susceptibility constants of Escherichia coli and Bacillus subtilis to silver and copper nanoparticles. Science of the Total Environment 373: 572-75. doi:10.1016/j.scitotenv.2006.11.007

Yosypchuk, B., and J. Barek. 2009. Analytical applications of solid and paste amalgam electrodes. Critical Reviews in Analytical Chemistry 39: 189-203. doi:10.1080/10408340903011838

Yosypchuk, B., and L. Novotny. 2002. Nontoxic electrodes of solid amalgams. Critical Reviews in Analytical Chemistry 32: 141-51. doi:10.1080/10408340290765498 